\title{
Reconocimiento de derechos sucesorios a las uniones de hecho declaradas judicial o notarialmente en Lima, durante el período 2004-2008 ${ }^{1}$
}

Recognition of Rights to Unions Probate Made Legal or Declared in Lima notary, During the Period 2004-2008

Liliana Magali Bellido Béjar ${ }^{2}$

http://dx.doi.org/10.21503/lex.v10i9.389

\section{Resumen}

El presente trabajo tiene como material de investigación el reconocimiento de los derechos sucesorios a las uniones de hecho. Así mismo, tiene como objetivo proponer la regulación plena y efectiva de los derechos sucesorios a los concubinos para erradicar, en consecuencia, el desamparo legal en que queda el supérstite ante la muerte de uno de ellos. El derecho como máxima expresión de Justicia no puede dejar de regular este tema que constituye una realidad de nuestra sociedad.

La metodología que se ha utilizado en la presente investigación es de tipo aplicativo, porque lo que se quiere es proponer que se otorguen derechos sucesorios a las uniones de hecho; el nivel de investigación es descriptivo por ser las uniones de hecho una realidad social, y correlacional por existir una relación entre las uniones de hecho y el derecho sucesorio; respecto al diseño de investigación, el procedimiento es no experimental porque ambas variables se comprueban con la realidad, siendo el recojo de datos de tipo cualitativo, estando a los motivos que dan origen al no reconocimiento de derechos sucesorios a las uniones de hecho.

Para la investigación, se ha tenido en cuenta el Derecho Comparado, considerando para ello una muestra compuesta por siete países donde se aplica el Derecho Sucesorio en las uniones de hecho, y una muestra de tres casaciones del Poder Judicial analizadas conjuntamente con el Derecho Nacional, obtenido como resultado (según el Kr-20) 0,95, lo cual supone un índice de significancia marcado, con lo que validamos nuestra hipótesis.

\footnotetext{
Esta tesis puede ser revisada en la biblioteca de la Universidad Alas Peruanas.

Título de abogada por la Universidad Alas Peruanas.
} 
Palabras clave: derecho sucesorio, uniones de hecho, fundamento del derecho sucesorio, principio constitucional de protección a la familia, vocación sucesoria, presupuestos legales.

\begin{abstract}
This research work "Recognition of the Rights of Succession to the Unions Done", is aimed at full and effective regulation of inheritance rights to domestic partners thus eradicating the legal helplessness. The law as the highest expression of justice cannot fail to regulate this issue is a reality in our society that is why it is imperative Probate law regulating the unions, before the death of one of them.

The methodology that was used in this investigation is Applicative type, because what we want is to grant inheritance rights to domestic partnerships, the level is Descriptive Research to be Done Unions a social reality, because there is a correlational relationship between domestic partnerships and Probate; respect to Research Design procedure is not experimental because both variables are checked against reality, with the gathering of qualitative data while the reasons that give rise to non-recognition of inheritance rights to domestic partnerships.

For the research has been as shown in Comparative Law comprises seven countries which apply the succession Law Unions in Fact and a sample of three cassations the Judiciary analyzed along with the National Law, resulting (as the KR-20) 0.95 pts., which is an index of marked significance, which validate our hypothesis.
\end{abstract}

Key words: succession rights, unions, basis of inheritance, constitutional principle of protection of the family, vocation probate, legal budgets. 


\section{Introducción}

Este trabajo de tesis tiene como materia de estudio y análisis la falta de reconocimiento de derechos sucesorios en las uniones de hecho que, con la normatividad vigente, tienen un tratamiento jurídico desfavorable debido a deficiencias normativas como son los vacíos legales. A partir de este estudio y análisis se tiene como fin proponer el otorgamiento de plenos reconocimientos sucesorios entre concubinos o convivientes.

En efecto, la investigación intenta plantear una solución posible a esta cuestión estudiando el tema desde diferentes perspectivas, porque así como se regula la constitución de dichas uniones, también se debe asignar efectos jurídicos ex post, es decir, después de la muerte de uno de los concubinos, de manera que los miembros de las uniones de hecho accedan a los derechos y obligaciones respectivos.

En tal sentido, nuestro ordenamiento jurídico debe avanzar hacia la protección de los derechos individuales y sucesorios en el marco de todo grupo que constituya una familia. El respeto a la diversidad y al libre desarrollo de la sociedad constituyen valores que deben informar un replanteamiento de nuestra legislación en esta materia.

El trabajo consta de cinco capítulos, y al final se muestran las conclusiones, recomendaciones, referencias bibliográficas, anexos, apéndices y un glosario de términos como información complementaria para el buen entendimiento de este trabajo.

\section{Objetivo general}

Identificar el perjuicio que ocasiona la falta de reconocimiento de derechos sucesorios a los concubinos, otorgándose en efecto un tratamiento jurídico desfavorable a las uniones de hecho declaradas judicial o notarialmente, a través de la normatividad vigente, con el fin regular el vacío legal existente en los artículos 816, 822, 823, 824 y 825 del Código Civil.

\section{Objetivos especificos}

a. Determinar si la falta de aplicación del Fundamento del Derecho de Sucesiones en las uniones de hecho declaradas judicial o notarialmente constituye una vulneración al Principio Constitucional de Protección a la Familia, con la finalidad de que este fundamento no solo sea de aplicación al matrimonio sino a todo grupo que sea concebido como familia.

b. Determinar el perjuicio que ocasiona la ausencia de Vocación Sucesoria entre concubinos afectando la existencia de las uniones de hecho que cumplen con los Presupuestos Legales, con el fin de acceder al patrimonio del causante. 


\section{Hipótesis principal}

Si se reconocen derechos sucesorios a los concubinos a través de una regulación al vacío legal existente, entonces se garantizaría la estabilidad de las uniones de hecho declaradas judicial o notarialmente.

\section{Hipótesis derivadas}

- Si no se aplica el Fundamento del Derecho de Sucesiones a las uniones de hecho declaradas judicial o notarialmente, entonces se constituye una vulneración al principio constitucional de protección a la familia, ocasionando desprotección legal.

- Si existe perjuicio por la ausencia de Vocación Sucesoria entre concubinos, entonces se afectará la existencia de las uniones de hecho que cumplen con los presupuestos legales, ocasionando que el sobreviviente no sea partícipe de la repartición de los bienes ante el deceso de uno de ellos.

\section{Conceptos importantes}

Afinidad. Parentesco que nace del matrimonio y se encuentra limitado al cónyuge, que queda unido a los parientes consanguíneos del otro. Los esposos no son afines; ellos son cónyuges. El esposo solo será afín con los consanguíneos de su mujer, y lo será en la misma línea y grado que lo viene a ser ella respecto de los suyos.

Bienes dotales. Bienes prestados por la mujer o por un tercero al marido, para que los administre y ayude a las necesidades del hogar. Bienes, en principio, inalienables y que el marido deberá restituir en caso de separación. En algunos Estados son inembargables, como para mantener intacto lo que constituiría un cierto bien de familia.

Bienes propios. Cualquiera de los bienes que cada uno de los cónyuges aporta al matrimonio y los que, luego de haberse celebrado, recibieren por herencia, legado o donación, y todo lo que se adquiriere con el producto de ellos. Serán también bienes propios los que se adquieren durante el matrimonio pero por causa anterior al mismo.

Bienes gananciales. Son bienes que cada uno de los cónyuges o ambos adquirieren en el matrimonio, por cualquier título que no fuere por herencia, un legado o donación, los que, por tal razón, les pertenecerán por iguales, como los adquiridos por el esfuerzo de alguno de ellos, por el azar, por rentas y por los frutos de bienes propios y/o comunes.

Concubinato. Es la convivencia de dos personas de diferente sexo y que no están unidas por el vínculo matrimonial. Es una relación que suele revestir un aspecto matrimonial, pues 
los concubinos conviven en el mismo domicilio, tienen hijos y aparentan ser, para la sociedad, tal como cónyuges, pero sin el amparo legal del que gozan estos últimos.

Causahabiente. En derecho civil, es el sujeto que se convierte en acreedor de un derecho como consecuencia de una transmisión, mortis causa, a título gratuito que le efectuara otro, en su beneficio, denominado causante. En un sentido más general, el heredero recibe, como tal, la denominación equivalente de "derechohabiente".

Consanguinidad. Es el parentesco que proviene de un común ascendiente y el que nace por comunidad de sangre que origina situaciones y relaciones que inciden en el derecho hereditario y de familia, asimismo en el procesal, civil o penal; constituye la forma de parentesco opuesta a la afinidad, y puede ser legítimo como extramatrimonial.

Cónynge supérstite. Es el que sobrevive al otro cónyuge, para el cual existen normas que lo amparan, referidas a los problemas que le crea la muerte de su consorte, tales como la regulación de bienes gananciales, el derecho sucesorio, el del hogar conyugal, el derecho de continuar con el uso y goce de una locación tras el fallecimiento del otro.

Herencia. Conjunto de bienes y cargas que formaban el patrimonio de una persona que al morir se transmite por su sucesión, testada o intestada; representa también el traspaso de los bienes a raíz de la defunción del causante, o el acervo de la herencia. Esta no solo es el acto de heredar sino además es una universalidad.

Heredero. Es sucesor universal, y continúa la persona del causante teniendo derecho de acrecer y de responder con sus propios bienes, mientras que el legatario es el sucesor singular que no confundirá su patrimonio con el del causante, ni continúa su persona, hereda el bien preciso y responde en su valor por las deudas del causante.

Herederos forzosos. El Código Civil en su artículo 3714 sostiene que "son herederos forzosos, aunque no sean instituidos en el testamento, aquellos a quienes la ley reserva en los bienes del difunto una porción de la que no puede privarlos sin justa causa de desheredación". No se invalidará la institución hereditaria, sino que salvará la legítima.

Indignidad. La vocación a recibir la herencia, surgida del parentesco o de la voluntad de un causante, refleja vínculos de afecto y de solidaridad. Pero, a veces, el heredero se vuelve indigno de ello. La ley lo excluye, entonces, de la herencia, y los que heredan por él o junto con él son los que podrían reclamar la herencia vacante.

Legitima. Parte del acervo del causante, de la cual los herederos no pueden ser privados sin justa causa de desheredación. Lo que todo testador pueda disponer libremente se llama 
porción disponible, y resultará repartible entre los herederos forzosos, por partes iguales, o asignable toda a uno de ellos, o a un extraño.

Partición. Actuación en la cual el heredero convierte su porción ideal, que le hubiere tocado en la herencia, en bienes más concretos, y por los que tendrá un derecho más exclusivo. La partición expresa una asignación y traduce los derechos de fracciones $(1 / 2,1 / 3)$ a bienes enteros y más concretos, lo que beneficiará al heredero.

Sociedad de hecho. O sociedad irregular, es la que nace por el simple hecho de que dos o más personas aportan sus bienes o servicios y desarrollan, mediante ellos, una producción económica en aras del beneficio común, pero sin cumplir con los recaudos legales que devienen necesarios para constituirse en una sociedad regular.

Sociedad conyugal. Copropiedad peculiar de carácter asociativo e indivisible afectada a preservar el hogar y cuya administración ha sido conferida por la ley a uno u otro de los cónyuges, según de donde provengan los bienes. Pueden serlos propios del marido o de la esposa, comunes o gananciales, lo que interesa para administrar o liquidar la sociedad.

Sucesión intestada. Procede el sucesorio ab intestato cuando el causante no hubiere testado, se declarare nulo o revocare el testamento, hubiere sido declarado indigno el heredero testamentario o haber este renunciado a percibir la herencia concedida a su favor. Tiene por objeto establecer si hay herederos del causante.

\section{Metodología}

\section{Tipo de investigación}

Aplicativo. Porque se considerarán derechos sucesorios a las uniones de hecho a fin de tutelar y garantizar la estabilidad de la familia de base no matrimonial.

\section{Nivel de investigación}

Descriptivo. Por ser las uniones de hecho una realidad social y cultural en crecimiento basada en las últimas estadísticas, y porque el no reconocimiento de derechos sucesorios constituye una incertidumbre jurídica frente al deceso de uno de los convivientes.

Correlacional. Por existir una relación entre las uniones de hecho y el derecho sucesorio, lo que da lugar a evaluar o analizar el derecho en referencia. 


\section{Diseño de investigación}

Por el procedimiento, es no experimental, porque el derecho sucesorio y las uniones de hecho se comprueban con la realidad, es decir, por ser formas observables o demostrables por sí solas, sin la necesidad de realizar pruebas científicas para su comprobación.

Por el recojo de datos es cualitativo, estando a los motivos que dan origen al no reconocimiento de derechos sucesorios a las uniones de hecho.

Por el tiempo, es de corte transversal, dado que para realizar su estudio se precisa un año de estudio. La realización de la investigación es en el corto plazo.

\section{Métodos de investigación}

Deductivo. La utilización de este método va a dar lugar a reconocer individualmente el porqué de la inaplicación de la legislación sucesoria en las uniones de hecho, dado que el Derecho no puede ignorar ni marginar esta realidad.

Inductivo. Permite identificar a las uniones de hecho, de manera que se aplique la legislación sucesoria para tutelar su estabilidad familiar.

Analítico-crítico. El problema de la inaplicación de legislación sucesoria en las uniones de hecho responde a muchas interrogantes que van a dar lugar a un profundo análisis, ya que es una realidad no solamente local o nacional sino también mundial; de ahí que se haga necesario tomar el tema con pinzas para desmenuzarlo y poder ofrecer una solución, sino total, al menos parcial.

Sintético. Se va a concluir aplicando alguna alternativa de solución parcial, tratándose de tema tan delicado.

Estadístico. Se realizará el procesamiento de datos necesario para la interpretación y análisis de los resultados de la investigación.

\section{Población y muestra}

- Tres (03) sentencias casatorias de derechos sucesorios en las uniones de hecho.

- Siete (7) países donde se aplica los derechos sucesorios en las uniones de hecho (Derecho Comparado).

- Un (1) abogado especialista en la materia. 


\section{Técnicas e instrumentos de recolección de datos}

Técnicas. Dado que el estudio supone el inicio de investigaciones futuras, se utilizarán en esta investigación las siguientes técnicas:

- Análisis documental

- Entrevista

- Estadística

Instrumentos

- Guía de análisis documentario.

- Guía de entrevista

- Excel o SPSS 19.0

Confiabilidad y validez del estudio

Validez. Para validar la lista de chequeo, se utilizará la validez por contenido.

Confiabilidad. Para determinar la confiabilidad de la muestra se utilizará el coeficiente de Kuder-Richardson (KR20), pues los indicadores presentan ítems que tienen como respuesta dos alternativas de tipo nominal. Su fórmula determina el grado de consistencia y precisión.

Para determinar el grado de confiabilidad del instrumento "De Derecho Comparado y Sentencias Casatorias en la Legislación Sucesoria respecto a las Uniones de Hecho", se determinó una muestra piloto de siete personas y tres sentencias casatorias del Poder Judicial, a fin de obtener el coeficiente de Consistencia Interna KR-20.

$$
r=\left(\frac{k}{k-1}\right)\left[1-\frac{\sum_{i=1}^{k} p_{i}\left(1-p_{i}\right)}{S^{2}}\right]
$$

Donde:

$p_{i}$ : proporción de indicadores.

$k$ : número de informes.

$S^{2}$ : varianza.

Finalmente, según la tabulación de datos de la Guía de Análisis Documental se obtuvo una confiabilidad de instrumento casi ideal, aplicando el coeficiente Kuder-Richardson (KR20), equivalente a 0,973 . 
Coeficiente Kuder -Richardson (KR-20): Guía de Análisis Documental:

\begin{tabular}{|c|c|}
\hline & Valor \\
\hline KR-20 & 0,973 \\
\hline
\end{tabular}

Tablas y análisis de datos

Tabla 1. Derecho sucesorio

\begin{tabular}{|c|c|c|c|c|}
\hline CAUSANTE & \multicolumn{2}{c|}{ D. COMPARADO } & \multicolumn{2}{c|}{ SENTENCIAS CASATORIAS } \\
\hline SÍ & 4 & 57,14 & 2 & 66,67 \\
\hline NO & 3 & 42,86 & 1 & 33,33 \\
\hline TOTAL & 7 & 100,00 & 3 & 100,00 \\
\hline
\end{tabular}

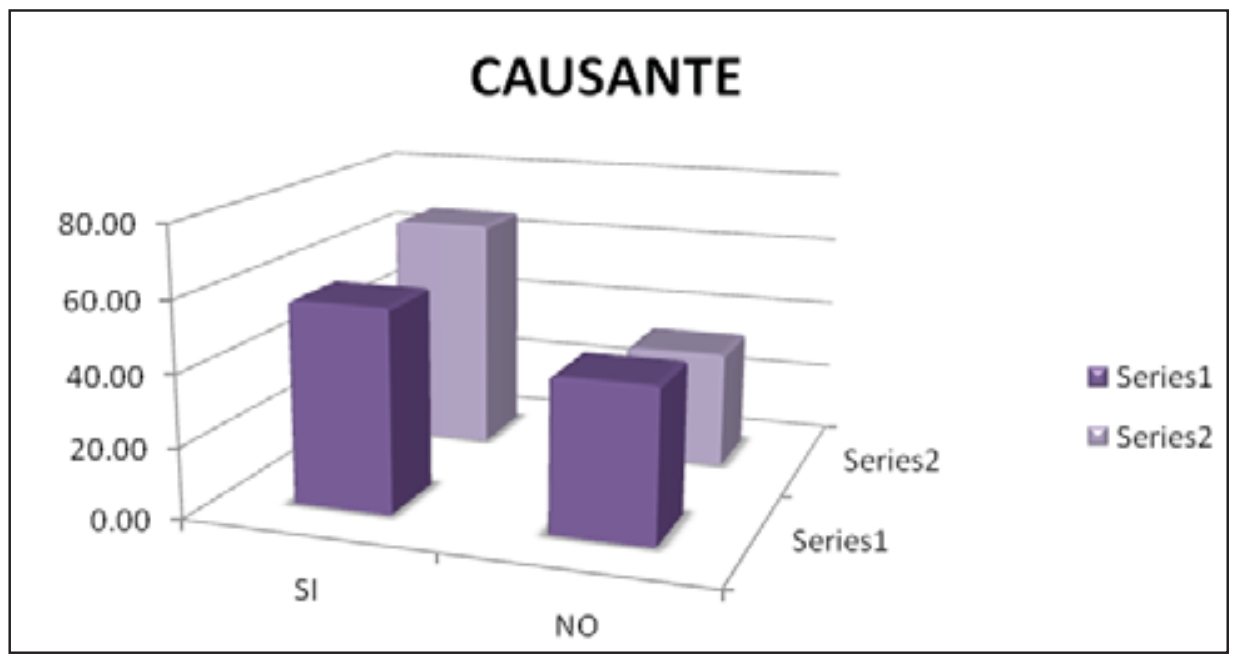

Figura 1

El causante (indicador P1) en cuatro países representa el 57\% y en dos sentencias casatorias representa el 28\%, donde sí se mencionó dicho indicador; en tres países equivale al $42 \%$ y en una sentencia casatoria equivale al 33\%, donde no se mencionó dicho indicador. Como podemos observar, tanto en el Derecho Comparado como en la Jurisprudencia se tiene al causante como aquel elemento que da origen a la sucesión. 
Tabla 2. Uniones de hecho

\begin{tabular}{|l|c|c|c|c|}
\hline \multirow{2}{*}{ UNIÓN VOLUNTARIA } & \multicolumn{2}{c|}{ D. COMPARADO } & \multicolumn{2}{c|}{$\begin{array}{c}\text { SENTENCIAS } \\
\text { CASATORIAS }\end{array}$} \\
\hline SÍ & 5 & 71,43 & 3 & 100,00 \\
\hline NO & 2 & 28,57 & 0 & 0,00 \\
\hline TOTAL & 7 & 100,00 & 3 & 100,00 \\
\hline
\end{tabular}

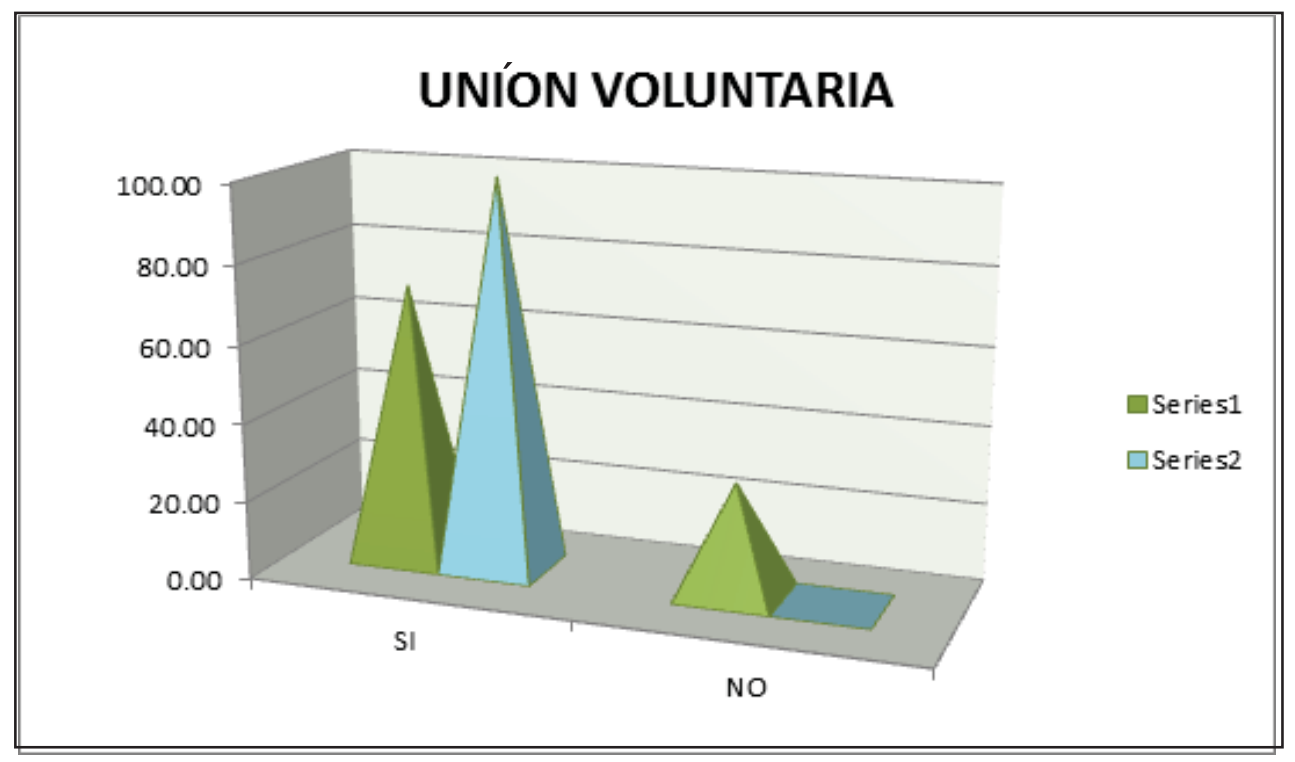

Figura 2

El indicador P4 (unión voluntaria) en cinco países representa el $71 \%$ y en tres sentencias casatorias representa el 100\%, donde sí se mencionó dicho indicador; en dos países equivale al $28 \%$, donde no se mencionó dicho indicador. En consecuencia, afirmaremos que tanto en la mayoría de países de la presente investigación (Derecho Comparado) como en la sentencia casatoria, la unión voluntaria es una de las características con la que deben cumplir las uniones de hecho.

Tabla 3. Fundamentos del derecho de sucesiones

\begin{tabular}{|l|c|c|c|c|}
\hline $\begin{array}{l}\text { PERPETUIDAD DEL DERECHO DE } \\
\text { PROPIEDAD }\end{array}$ & \multicolumn{2}{|c|}{ D. COMPARADO } & \multicolumn{2}{|c|}{$\begin{array}{l}\text { SENTENCIAS } \\
\text { CASATORIAS }\end{array}$} \\
\hline SÍ & 5 & 71,43 & 0 & 0,00 \\
\hline NO & 2 & 28,57 & 3 & 100,00 \\
\hline TOTAL & 7 & 100,00 & 3 & 100,00 \\
\hline
\end{tabular}




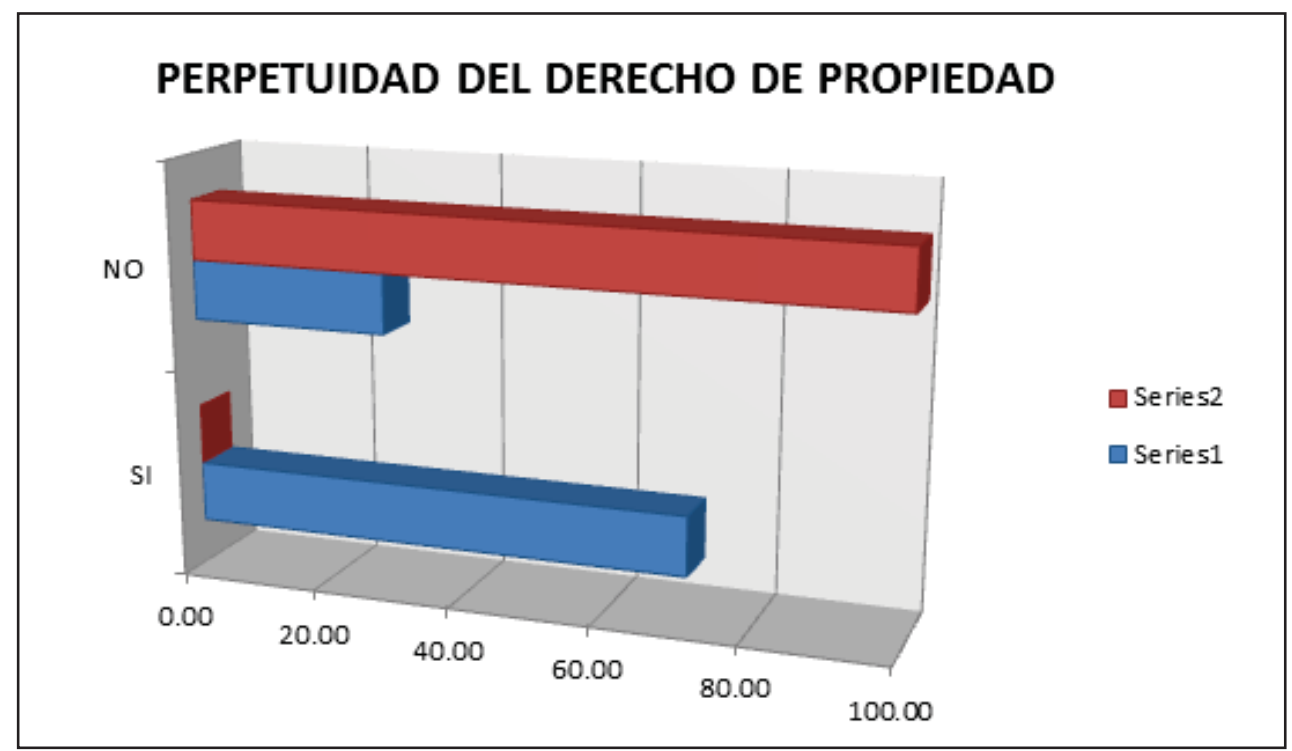

Figura 3

El indicador P7 (perpetuidad del derecho de propiedad), en cinco países representa el $71 \%$, donde sí se mencionó dicho indicador; en tres países equivale al $42 \%$ y en tres sentencias casatorias equivale al 100\%, donde no se mencionó dicho indicador. En la mayoría de países (Derecho Comparado), se garantiza la perpetuidad del derecho de propiedad, y esta se extiende hacia las uniones de hecho, lo que no sucede en nuestro país.

Tabla 4

\begin{tabular}{|l|c|c|c|c|}
\hline $\begin{array}{l}\text { CONSIDERACIONES AFECTIVAS } \\
\text { Y PSICOLÓGICAS }\end{array}$ & \multicolumn{2}{|c|}{$\begin{array}{l}\text { SENTENCIAS } \\
\text { CASATORIAS }\end{array}$} \\
\hline SÍ & 5 & 71,43 & 0 & 0,00 \\
\hline NO & 2 & 28,57 & 3 & 100,00 \\
\hline TOTAL & 7 & 100,00 & 3 & 100,00 \\
\hline
\end{tabular}




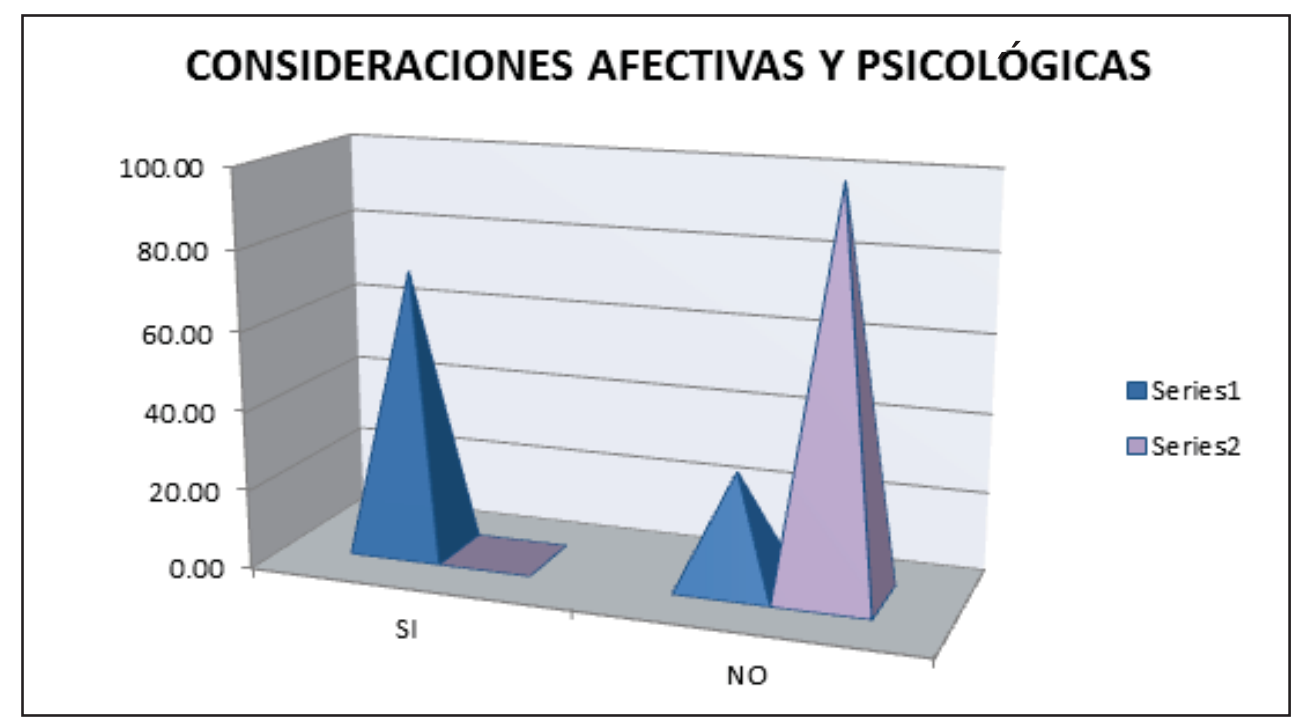

Figura 4

El indicador P8 (consideraciones afectivas y psicológicas), en cinco países representa el $71 \%$, donde sí se mencionó dicho indicador; en dos países equivale al $28 \%$ y en tres sentencias casatorias equivale al $100 \%$, donde no se mencionó dicho indicador. Como podemos observar en el Derecho Comparado, este indicador es muy importante ya considera que el causante trabaja en vida para asegurar la asistencia de sus descendientes y de su cónyuge, resultando ilógico que después de su muerte no se preocupara de ello. En nuestro país este indicador no se aplica en su totalidad, ya que las uniones de hecho no gozan del Derecho Sucesorio.

Tabla 5. Principio constitucional de protección a la familia

\begin{tabular}{|l|c|c|c|c|}
\hline $\begin{array}{l}\text { DERECHO DE LOS MIEMBROS DE } \\
\text { UNA FAMILIA A RECIBIR IGUAL } \\
\text { PROTECCIÓN }\end{array}$ & \multicolumn{2}{|c|}{ D. COMPARADO } & \multicolumn{2}{|c|}{$\begin{array}{l}\text { SENTENCIAS } \\
\text { CASATORIAS }\end{array}$} \\
\hline SÍ & 6 & 85,71 & 0 & 0,00 \\
\hline NO & 1 & 14,29 & 3 & 100,00 \\
\hline TOTAL & 7 & 100,00 & 3 & 100,00 \\
\hline
\end{tabular}




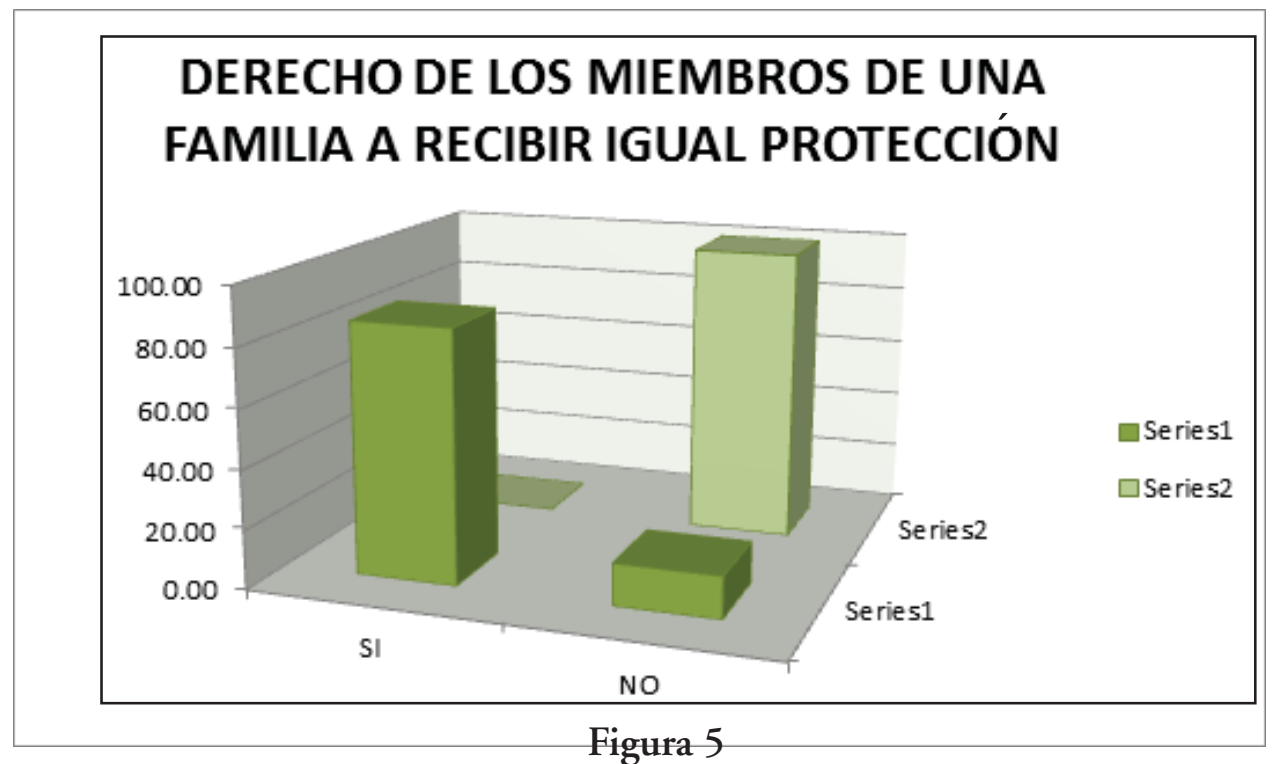

El indicador P10 (derecho de los miembros de una familia a recibir igual protección), en seis países representa el 85\%, donde sí se mencionó a dicho indicador; en un país equivale al 14\% y en tres sentencias casatorias al $100 \%$, donde no se mencionó dicho indicador. El derecho de los miembros de una familia a recibir igual protección es muy bien garantizado en otros países, a diferencia del nuestro, ya que no se extiende a todo grupo que pueda ser considerado familia. De ser así, entonces se otorgaría el derecho sucesorio a los concubinos.

Tabla 6. Vocación sucesoria

\begin{tabular}{|l|c|c|c|c|}
\hline VOLUNTAD DEL CAUSANTE & \multicolumn{2}{|c|}{ D. COMPARADO } & \multicolumn{2}{|c|}{$\begin{array}{l}\text { SENTENCIAS } \\
\text { CASATORIAS }\end{array}$} \\
\hline SÍ & 7 & 100,00 & 1 & 33,33 \\
\hline NO & 0 & 0,00 & 2 & 66,67 \\
\hline TOTAL & 7 & 100,00 & 3 & 100,00 \\
\hline
\end{tabular}




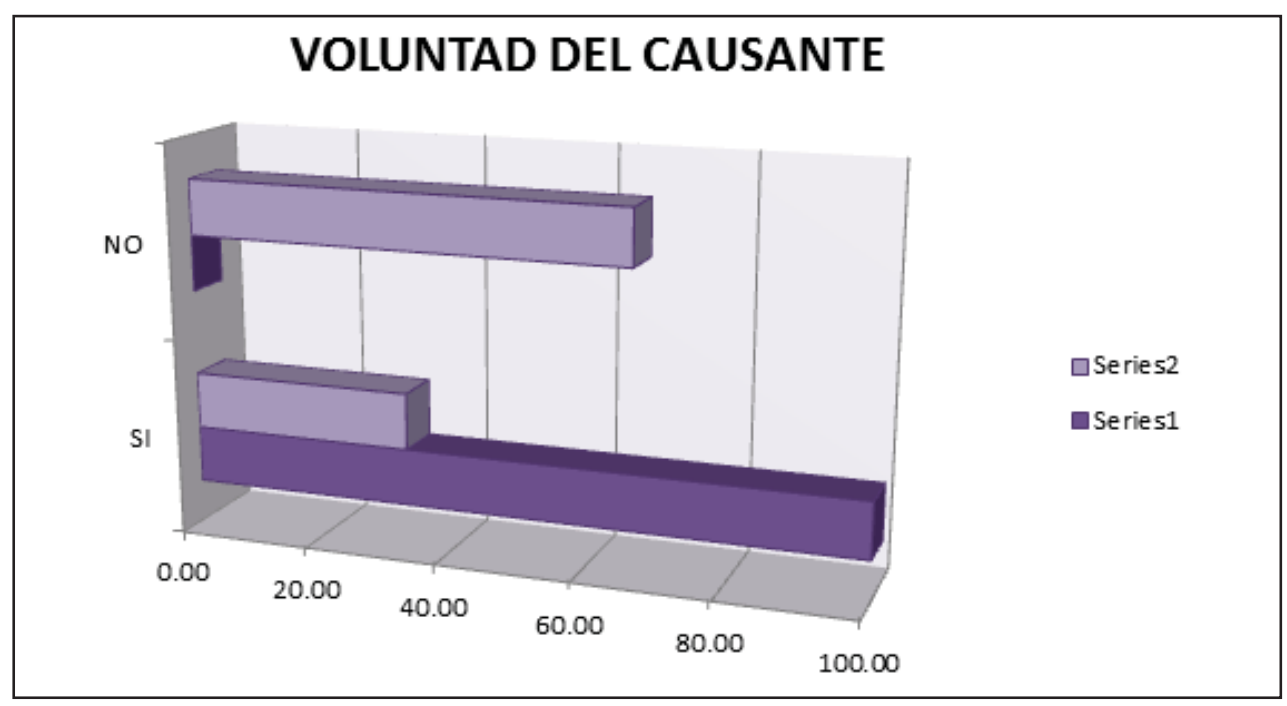

Figura 6

El indicador P13 (voluntad del causante), en siete países representa el 100\% y en una sentencia casatoria el 33\%, donde sí se mencionó a dicho indicador; en dos sentencias casatorias equivale al 66\%, donde no se mencionó a dicho indicador. Este indicador se refiere a que el testador está totalmente facultado para instituir legatarios ante la ausencia de herederos forzosos, entre los que no están los concubinos; es decir, el concubino queda a expensas de la voluntad del testador y no de la ley.

\section{Conclusiones}

1. Al reconocerse derechos sucesorios a los concubinos, se garantiza su estabilidad, dándose un tratamiento eficaz a las uniones de hecho declaradas judicial o notarialmente a través de una regulación al vacío legal existente. Es decir, lo que se quiere es aplicar la teoría reguladora a estas uniones y atender a una necesidad de regulación integral, ya que las uniones de hecho deben ser reconocidas y legalizadas por constituir un fenómeno social que ha existido, existe y existirá siempre, no pudiendo el Derecho negar su existencia, como la ley no puede dejar de regular las consecuencias jurídicas. Además, ni los convivientes ni los hijos deben ser discriminados en sus derechos tanto personales como patrimoniales debido a la no existencia de vínculo matrimonial, debiendo contar entonces con soluciones claras y objetivas que no queden sujetas, en consecuencia, al criterio variable de los jueces, pues en ellas el justiciable está abandonado al criterio de los tribunales de justicia, que, a falta 
de norma positiva, aplican analógicamente su razonamiento. Es así que al haber utilizado al Derecho Comparado en nuestra investigación, vemos que en otros países se muestra una gran evolución legislativa, ya casi superada, a diferencia del nuestro, que regula este tipo de situaciones.

2. La falta de aplicación del Fundamento del Derecho de Sucesiones en las uniones de hecho declaradas judicial o notarialmente constituye una vulneración del Principio Constitucional de Protección a la Familia, ocasionando desprotección legal. La jurisprudencia constitucional ha desarrollado el concepto de familia, determinando en primer lugar que en la actualidad existe una pluralidad de estructuras familiares, todas merecedoras de igual protección y tutela. Esta perspectiva enriquece la visión que debe tenerse de la realidad, siendo que la familia es una entidad ético-social que responde a los fenómenos sociales y culturales, reconfigurando con ello su estructura. Asimismo, el propio Tribunal Constitucional define a dichas uniones como un tipo de familia merecedora de la tutela del Estado frente a cualquier amenaza o lesión por parte del Estado y la sociedad, tal como lo demanda el texto constitucional y los tratados internacionales de derechos humanos. Siendo ello así, deben reconocerse a plenitud a las uniones de hecho todos los derechos que emanan de su propia naturaleza así como los derechos sucesorios. Así, si la construcción jurisprudencial ya ha establecido cuál es la esencia de la familia, sería más práctico que lo recogiera a través de la norma legal. Es así que el propio Código Civil en el artículo 233 establece lo siguiente: "La regulación jurídica de la familia se realiza en armonía con los principios y normas proclamados en la Constitución".

3. El perjuicio por la ausencia de Vocación Sucesoria entre concubinos afecta la existencia de las uniones de hecho que cumplen con los presupuestos legales, ocasionando que no sean partícipes de la repartición de los bienes ante el deceso de uno de ellos. Siendo que entre las uniones de hecho no hay sucesores legítimos, es decir, no hay herederos forzosos, y por lo cual no tienen vocación hereditaria, pese a que cumplen con todos los presupuestos legales que la normatividad exige, $y$ en efecto tienen fines parecidos al matrimonio, entonces lo que se pretende de manera justa es otorgarle la misma vocación sucesoria por la proximidad de grado que tiene el concubino al igual que el cónyuge, reservándole en consecuencia la ley una parte intangible del patrimonio del causante, que obligatoriamente le correspondería sin limitación alguna. En efecto, en nuestra realidad para tener derecho sucesorio es necesario que la pareja haya contraído matrimonio civil, ya que el Código Civil establece que el conviviente solo tiene derecho a los bienes que haya concebido en común con el viudo a la viuda, esto es, por la sociedad de gananciales que entre ellos existe, lo cual constituye un total desamparo legal. 


\section{Recomendaciones}

1. A fin de que se elimine el perjuicio que ocasiona la falta de reconocimiento de derechos sucesorios a los concubinos, debe otorgarse en efecto un tratamiento jurídico a las uniones de hecho declaradas judicial o notarialmente a través de la normatividad vigente, regulando el vacío legal existente en los artículos 816, 822, 823, 824 y 825 del Código Civil, incluyendo al concubino conjuntamente con el cónyuge a participar del derecho de sucesiones, con el fin de erradicar el desamparo legal. Sin perjuicio de una eventual regulación general de la convivencia, una pequeña regulación de las normas del Derecho Sucesorio puede producir un interesante espacio de libertad para los convivientes, que les permitiría favorecer a las uniones de hecho, sin perjudicar a nadie. (Anexo 1 - Proyecto de Ley)

2. Constituye una imperiosa necesidad la aplicación del Fundamento del Derecho de Sucesiones en las uniones de hecho declaradas judicial o notarialmente, de modo que en efecto no se vulnere el Principio Constitucional de Protección a la Familia, con la finalidad de que este fundamento no solo sea de aplicación al matrimonio sino a todo grupo que sea concebido como familia, como son las uniones de hecho. La legislación nacional referida a aspectos específicos de las uniones de hecho ha situado correctamente a estas en el ámbito del derecho de familia, abandonando irrevocablemente la mirada al derecho de sucesiones.

3. Es necesario que el Estado otorgue Vocación Sucesoria a los concubinos de manera que no afecte la existencia de las uniones de hecho que cumplen con los presupuestos legales, con el fin de acceder al patrimonio del causante. Es así que el Derecho debería concentrar sus esfuerzos en desplegar sus efectos allí donde tiene alguna posibilidad de efectividad y eficacia. En cualquier caso, como fenómeno social, las uniones de hecho, hoy en día, tan igual como ocurre con el matrimonio, crean situaciones familiares que deben ser atendidas por el Derecho. 


\section{Referencias}

- Baqueiro, E., Buenrostro, R. (1994). Derecho de Familia y Sucesiones (1era. edición). México: Talleres Impresora Publimex S.A.

- Baldassarre, A. Los derechos sociales (1era. reimpresión). Lima: Universidad Externado de Colombia.

- Bellucio A. (1967). Nociones de Derecho de Familia (1era. edición). Buenos Aires: BBAA.

- Berrio B. (2002).Nuevo Código Civil (2da. edición). Lima: Gaceta Jurídica S.A.

- Bossert G. (1982). Régimen jurídico del concubino (1era. edición). Buenos Aires: Editorial Astrea.

- Canduelas, M. (2004). Manual de Derecho de Sucesiones (1era. edición). Lima: Cepejac Asociación Civil.

- Cornejo H. (1999). Derecho Familiar Peruano (10ma. edición). Lima: Gaceta Jurídica.

- Corral H. (2005). Derechos y Derecho de Familia (1 era. edición). Lima: Grijley E.I.R.L.

- Fernández. C. (2003). Código Civil: Derecho de Sucesiones (1era. Edición). Lima: Fondo Editorial de la Pontificia Universidad Católica del Perú.

- Hurtado E. (1988). Propuestas para la creación del régimen de bienes entre concubinos (1 era. edición). Bogotá: Temis.

- Peralta R. (2008). Derecho de Familia en el Código Civil (4ta. edición). Lima: Moreno S.A.

- Peralta R. (1995). Derecho de Familia (2da. Edición). Lima: Idemsa.

- Plácido A. (2001). Manual de Derecho de Familia (1era. Edición). Lima: Gaceta Jurídica S.A.

- Plácido A. (2002). Los regímenes patrimoniales del matrimonio (1era. edición). Lima: Gaceta Jurídica S.A.

- Quisbert E. (2007). Introducción al Derecho de Sucesiones (1era. edición). La Paz: Adeq.

Tesis

- Alegre M. (2008). Unión de hecho vista a través de la Constitución. Tesis de Derecho y Ciencias Políticas, Universidad de San Martín de Porres. Lima. 
- Brito J. (2010). La prueba judicial del concubinato en el Derecho venezolano. Tesis de Ciencias Jurídicas, Universidad Rafael Urdaneta. Caracas.

- Hidalgo K. (2004). Derechos sucesorios de los convivientes en el marco de la unión no matrimonial. Tesis de Ciencias Jurídicas, Universidad Francisco Gavidia. San Salvador.

- Tapia A. y Vives C. (2003). Derechos hereditarios en las uniones de hecho. Tesis de Derecho y Ciencias Políticas, Universidad Señor de Sipán de Chiclayo. Chiclayo.

- Saravia R. (2005). Unión de hecho y derecho de sucesiones en el Perú. Tesis de Derecho y Ciencias Políticas, Universidad Nacional Jorge Basadre Grohmann. Tacna.

Hemerográficas

- Ballesteros J. (1999). La Unión Libre o Marital. Revista de Derecho Privado.Chile.

- Reyes N. (2005). La familia no matrimonial en el Perú. Revista de Derecho de la Facultad de Derecho y Ciencia Politica de la UNMSM. Lima.

- Varas J. (2010). Uniones de hecho y Derecho Sucesorio. Revista de Derecho. Chile.

- Vigil C. (2003).Los concubinos y el Derecho Sucesorio en el Código Civil Peruano. Revista de Investigación de la Facultad de Derecho y CC.PP de la UNMSM. Lima.

Electrónicas

- Corcuera P. (2011). En el 2010 Perú registró solo 2,8 matrimonios por mil habitantes; además ocupa el segundo puesto en cohabitación. Instituto de Ciencias para la Familia de la Universidad de Piura. (26/02/12)._http://familiaperuana.wordpress.com/

- Díaz A. (2010). El Concubinato como problema jurídico. Revista Electrónica del Trabajador Judicial. (15/03/12). http://trabajadorjudicial.wordpress.com/el-concubinato-comoproblema-juridico/

- INEI (2007). Censos Nacionales 2007: XI de Población y VI de Vivienda. (20/01/12). http:// www.inei.gob.pe/Anexos/libro.pdf

- INEI (2007). Características de la Población. (13/03/12). http://www.inei.gob.pel biblioineipub/bancopub/Est/Lib0838/libro19/cap01.pdf Infoleyes Bolivia. Código Civil de Bolivia. (15/01/12). http://bolivia.infoleyes.com/shownorm.php?id=821

Instituto de Investigaciones Jurídicas. Código Civil Federal. (05/02/12) http://info4. juridicas.unam.mx/ijure/tcfed/1.htm?s 
- Instituto de Sociología (2008). Matrimonio y convivencia a la luz de la Encuesta Bicentenario. $(12 / 03 / 12)$.

- http://www.pasa.cl/wpcontent/uploads/2011/08/Familia_y_Conyugalidad_encuesta_ bicentenario.pdf

- Luz Amparo Callapiña Cosío (2001). Reconocimiento de la unión de hecho en sede notarial $y$ las implicancias en la comunidad de bienes. (02/04/11).

- http://juspedia.com/index.php?url=reconocimiento_de_la_uni\%D3n_de_hecho_en_ sede_notarial

- Ministerio de Justicia y de Derechos Humanos. Ley $N^{\circ} 1 / 92$ Reforma parcial del Código Civil. (012/03/12)

- http://www.biblioteca.jus.gov.ar/Codigo-Civil-Paraguay-reformaparcial.html

- Noticias Jurídicas. Ley 2/2003, Ley reguladora de las parejas de hecho. (16/03/12) http:// noticias.juridicas.com/base_datos/CCAA/pv-12-2003.html

- Noticias Jurídicas. Ley 6/1999, Ley relativa a parejas estables no casadas. (12/02/12) http:// noticias.juridicas.com/base_datos/Derogadas/r2-ar-16-1999.html

- Plácido A. (2008). El principio de reconocimiento integral de las uniones de hecho (la prueba de la existencia de la unión de hecho).Investigaciones y artículos jurídicos sobre derecho de familia, de niños y adolescentes y de sucesiones. (03/02/12) http://blog.pucp.edu. pe/archive/1188/2008-04

- Poder Legislativo de la República de Uruguay. Ley No 18.246 De Uniones Concubinarias de la República del Uruguay. (09/02/12) http://sip.parlamento.gub.uy/leyes/AccesoTextoLey. asp?Ley=18246\&Anchor $=$

- Poder Judicial. Jurisprudencia sistematizada. (03/02/12). http://jurisconsulta.pj.gob.pe/ jurisWeb/faces/SearchParameters.jsp

- Sandoval J. (2003). Perú registra una de las tasas de matrimonio más bajas del mundo, según estudio. Andina, agencia peruana de noticias. (27/01/12)_http://www.andina.com. $\mathrm{pe} /$ Espanol/noticia-peru-registra-una-las-tasas-matrimonio-mas-bajas-del-mundo-segunestudio-384892.aspx

- Tribunal Constitucional del Perú. Sentencia del Tribunal Constitucional. (05/01/12) http:// www.tc.gob.pe/jurisprudencia/2008/06572-2006-AA.html 
- Tribunal Supremo Electoral. Constitución Politica de Bolivia. (05/03/12) http://www.oep. org.bo/proces_electoral/RefConstitucion2009/documentos/CPEVigente.pdf

- Universidad de Zaragoza. Ley 2/2004, de 3 de mayo, de modificación de la Ley 6/1999, de 26 de marzo, relativa a parejas estables no casadas. Tramitación Parlamentaria. (03/04/12) http://www.unizar.es/derecho/standum_est_chartae/weblog/rdca/rdcaixx/d18.pdf 
Este libro se terminó de imprimir en los talles gráficos de la Universidad Alas Peruanas,

Los Gorriones 264, Chorrillos.

Lima, Perú.

Agosto, 2012 